\title{
Effects of a Weight Loss Program on Metabolic Syndrome, Eating Disorders and Psychological Outcomes: Mediation by Endocannabinoids?
}

\author{
Zoltan Pataky ${ }^{a} \quad$ Isabelle Carrard ${ }^{a}, b \quad$ Valerie Gay ${ }^{a}$ Aurélien Thomas ${ }^{c}$ \\ Anne Carpentier $^{\mathrm{a}} \quad$ Elisabetta Bobbioni-Harsch ${ }^{a}$ Alain Golay ${ }^{\mathrm{a}}$ \\ aService of Therapeutic Education for Chronic Diseases, WHO Collaborating Center, \\ University Hospitals of Geneva and University of Geneva, Geneva, Switzerland; \\ ${ }^{b}$ Department of Nutrition and Dietetics, School of Health Sciences, University of Applied \\ Sciences and Arts Western Switzerland (HES-SO), Geneva, Switzerland; ' Unit of Toxicology, \\ CURML, University Hospitals of Geneva and University of Geneva, Geneva, Switzerland
}

\section{Keywords}

Weight loss · Metabolic syndrome · Endocannabinoids · Eating disorders · Quality of life ·

Patient education

\begin{abstract}
Objective: To evaluate the effects of weight loss on endocannabinoids, cardiometabolic and psychological parameters, eating disorders (ED) as well as quality of life (QoL) and to elucidate the role of endocannabinoids in metabolic syndrome (MS). Methods: In total, 114 patients with obesity were prospectively included in a 12-month weight loss program. Plasma endocannabinoids were measured by mass spectrometry; ED, psychological and QoL-related parameters were evaluated by self-reported questionnaires; physical activity was measured by accelerometer. Nutritional assessment was done by a 3-day food diary. Results: Among completers $(n=87)$, body weight decreased in 35 patients $(-9.1 \pm 8.6 \mathrm{~kg})$, remained stable in 39 patients, and increased in 13 patients $(+5.8 \pm 3.4 \mathrm{~kg}) .75 \%$ of patients with MS at baseline were free of MS at follow-up, and their baseline plasma N-palmitoylethanolamide (PEA) values were significantly lower when compared to patients with persisting MS. At baseline, there was a positive relationship between PEA and waist circumference $\left(p=0.005, R^{2}=0.08\right)$, fasting glucose $\left(p<0.0001, R^{2}=0.12\right)$, total cholesterol $\left(p=0.001, R^{2}=0.11\right)$, triglycerides $(p=0.001$, $\left.R^{2}=0.11\right)$, LDL-cholesterol $\left(p=0.03, R^{2}=0.05\right)$ as well as depression score $\left(p=0.002, R^{2}=\right.$ 0.29). Conclusion: Plasma PEA might play a role in metabolic improvement after weight loss. Even in subjects without weight loss, a multidisciplinary intervention improves psychological outcomes, ED, and QoL.




\section{Introduction}

Numerous conservative weight loss programs for obese patients have been described. Despite significant improvements of metabolic and cardiovascular outcomes, even after moderate or modest weight loss, the implementation of these programs into clinical practice seems to be difficult and subject to a substantial attrition rate. The complexity of interventions, limited weight loss, and the relapse could be the main reasons for the failure of implementation of a non-surgical weight loss program.

A commonly recommended weight loss by lifestyle intervention in people with obesity is $5-10 \%$ reduction in baseline weight [1]. It has been well documented that moderate weight loss has an important impact on the onset and progression of type 2 diabetes and related co-morbidities, lipid disorders as well as hypertension, and could be cost-effective [2-5]. In the Diabetes Prevention Program (DPP), a mean weight loss of $5.6 \mathrm{~kg}$ at 2.8 years resulted in a 58\% relative reduction in the risk of type 2 diabetes [2]. Recently, Magkos et al. [5] have shown that a $5 \%$ weight loss was associated with significant improvement of body composition and multiple cardiometabolic risk factors as well as an improvement of insulin sensitivity and overall $\beta$-cell function. Further weight loss is related to stepwise reduction of cardiometabolic risk factors in the majority of studies.

In both clinical and research settings, it is much easier to achieve and maintain a smaller extent of weight loss. However, most patients regain weight due to decrease of motivation and adherence both to diet and physical activity prescriptions, after only several months.

On the other hand, the improvement of the psychosocial well-being of an obese subject after a modest weight loss is often underestimated. Furthermore, psychological disorders associated with obesity can be reduced and quality of life (QoL) improved by lifestyle changes even in the absence of weight loss [6,7]. It is matter of fact that overweight and obesity have a major and negative impact on mood, QoL, self-esteem, and self-confidence, which, in turn, negatively influence the social life and integration of the patient in the society and generate additional costs. Surprisingly, only a limited number of lifestyle intervention studies has incorporated self-reported psychological measures of well-being and QoL related to obesity. Lifestyle interventional programs are mainly focusing on weight modifications and metabolic improvements.

The endocannabinoids play an important role in the control of food intake, energy balance, and reward mechanisms [8-10]. We have recently shown that plasma N-palmitoylethanolamide (PEA) is correlated with coronary function which could be a functional precursor of coronary heart disease in obesity [11]. Data on the relationship between plasma endocannabinoids on one side and metabolic syndrome (MS) or depression on the other side are missing, and the role of endocannabinoids in the evolution of health-related outcomes is poorly understood.

Our aim was to evaluate the impact of a multidisciplinary and structured non-dieting weight loss program on metabolic and psychological parameters, eating disorders (ED), and QoL in obese primary care patients. We further evaluate the relationship between plasma endocannabinoids and the evolution of weight, cardiometabolic and psychological parameters.

\section{Subjects and Methods}

\section{Studied Population}

A total number of 114 patients with obesity have been prospectively recruited at the University Hospitals of Geneva, Service of Therapeutic Education for Chronic Diseases, after their signed the written consent. The study protocol was approved by the local ethical committee. 
Pataky et al.: Effects of a Weight Loss Program on Metabolic Syndrome, Eating Disorders and Psychological Outcomes: Mediation by Endocannabinoids?

At baseline, 95 women (age $45.6 \pm 10.5$ years, BMI $37.0 \pm 5.7 \mathrm{~kg} / \mathrm{m}^{2}$ ) and 19 men (age $45.8 \pm 9.9$ years, BMI $38.8 \pm 4.6 \mathrm{~kg} / \mathrm{m}^{2}$ ) who fulfilled the study inclusion criteria agreed to participate in the study. Inclusion criteria were based on the presence of overweight or obesity in patients addressed for a weight loss program in the Service of Therapeutic Patient Education for Chronic Diseases, University Hospitals of Geneva.

\section{Multidisciplinary Weight Loss Program}

The Service of Therapeutic Education for Chronic Diseases is a WHO collaborating and reference center for chronic disease management, particularly engaged in therapeutic patient education in the field of obesity and diabetes. The evaluated lifestyle intervention for weight loss is a multidisciplinary and structured patient educational program for obese patients over 12 months, with a minimum of 9 group sessions and 10 individual outpatient appointments during the program duration. Each group session, of whole day duration (from 9 a.m. to 5 p.m.) consists of several workshops having a specific structure, depending on the topic (e.g., diet, eating behavior, physical activity).

At the beginning of the program, patients are required to participate in a predefined curriculum including on medical issues, balanced diet, cognitive-behavioral therapy, physical activity, and art therapy over 4 consecutive days. During these 4 days, every patient has individual appointments with different healthcare providers (HCP) and specialists (e.g., physician, nurse, dietician, and psychologist) for medical, nutritional and psychological assessment on an interdisciplinary basis. Moreover, group sessions take place and are managed by the HCP according to the workshop's topic. This 4-day (full time) educational program is followed by a coaching that takes place over the following 12 months. During this period, every patient participates in a minimum of 4 ambulatory, motivational and educational group sessions (every 2-3 months), each with different topic (i.e., diet, cognitive-behavioral therapy, physical activity, and body image) taking 1 day each.

A personal coach (i.e., an HCP specialized in both obesity management and patient education) is attributed to every patient. The patient has a follow-up on regular monthly basis with this HCP and during the 12-month follow-up period. His/her body weight is measured monthly during each 60-min individual appointment. During these face-to-face meetings, different aspects of healthy nutrition and physical activity are discussed with the patient, as well as the difficulties related to psychological and environmental issues (e.g., family, work, social live). The face-to-face meetings are individually tailored and are based on motivational interviewing $[12,13]$, and any diet or physical activity prescription is proposed to the patient.

At the end of the 12-month period, patients are required to participate in the last workshop day centered on results after 12 months. In addition to biological evaluation (e.g., fasting glucose, HbA1c, lipids, liver parameters, and blood pressure), group sessions and individual appointments take place during the day in order to assess the psychosocial well-being and QoL of every participant.

According to the study protocol, blood samples and questionnaires were collected at baseline and after 12 months of the weight loss program.

\section{Biological and Laboratory Measurements}

Body weight, \% body fat and fat-free mass were evaluated by the TANITA ${ }^{\circledR}$ bioimpedance scale (Tanita International Division, Yiewsley, UK).

Total cholesterol, high-density lipoprotein cholesterol (HDL-cholesterol) and triglycerides were measured by Roche enzymatic colorimetric methods for modular systems (Hoffmann La-Roche Ltd, Basel, Switzerland). Low-density lipoprotein cholesterol (LDL-cholesterol) concentration was calculated by the Friedewald formula [14]. Glucose, HbA1c, ASAT, ALAT, GGT and high-sensitivity-C-reactive protein (hs-CRP) were routinely measured.

MS was defined according to the International Diabetes Federation (IDF) Guidelines for the Diagnosis of the Metabolic Syndrome [15]. Namely, fasting glucose $\geq 5.6 \mathrm{mmol} / \mathrm{l}$, fasting triglycerides $\geq 1.7 \mathrm{mmol} / \mathrm{l}$, HDL cholesterol $<1.03$ in men and $<1.29 \mathrm{mmol} / \mathrm{l}$ in women, and blood pressure $\geq 130 / 85 \mathrm{~mm} \mathrm{Hg}$. Waist circumference was pathological in all subjects as was expected with respect to the population studied.

\section{Endocannabinoid Measurement}

Plasma levels of $\mathrm{N}$-arachidonoylethanolamide (AEA), 2-arachidonoylglycerol (2-AG), N-oleoylethanolamide (OEA),PEA were determined from peripheral arm vein blood samples. AEA, 2-AG, OEA, and PEA were extracted from $100 \mu \mathrm{l}$ of plasma by liquid-liquid extraction and separated by liquid chromatography (Ultimate 3000 RS; Dionex, Sunnyvale, CA, USA). Analyses were performed on a 5500 QTrap (triple quadrupole/linear ion trap) mass spectrometer equipped with a TurboIon-Spray ${ }^{\mathrm{TM}}$ interface (AB Sciex, Concord, ON, Canada) [16]. 
Pataky et al.: Effects of a Weight Loss Program on Metabolic Syndrome, Eating

Disorders and Psychological Outcomes: Mediation by Endocannabinoids?

Blood Pressure and Heart Rate Assessment

Sitting blood pressure and heart rate are the mean values of three measurements (OMRON $705 \mathrm{cp}$, OMRON Healthcare Europe, Hoofddorp, The Netherlands).

\section{Basal Metabolic Rate Measurement}

Basal metabolic rate was measured by using indirect calorimetry method (Deltatrac-Ohmeda; Datex, Duisburg, Germany). Prior to each test, the analyzer was calibrated. Patients rested for at least 30 min before data were collected. Energy expenditure was calculated using the Weir equation with an algorithm provided by the manufacturer [17].

\section{Nutritional Assessment}

Both at baseline and after 12 months, the patients filled in a 3-day paper food diary, including 2 week days and 1 weekend day. The daily caloric intake and diet composition were calculated with the Prodi ${ }^{\circledR}$ software, version 5 (Nutri-Science GmbH, Hausach, Germany).

We calculated the ratio energy intake/basal metabolic rate to identify misreporting. Values of the ratio lower than 1.35 were recognized as underreporting [18].

\section{Assessment of Physical Activity}

Physical activity was measured by a small single-axis accelerometer (Actigraph, AM7164-2.2; Computer Science and Applications, Pensacola, FL, USA) [19, 20]. The acceleration signal was digitized with 10 samples/s, registered as counts over 1-min intervals. The accelerometer was worn for up to 4 days on a belt in the small of the back, from waking to bedtime except during water-based activities. We analyzed participants with at least 3 days of data, including days when the device was worn more than $10 \mathrm{~h}$; we assumed it was not worn if there were 60 consecutive minutes with no counts. Data were checked for spurious recording: high counts $>20,000$ counts/min or repeated counts [21]. Daily physical activity was calculated as average number of counts/min when accelerometer was worn.

Evaluation of Depression and Anxiety by Self-Questionnaires

Beck Depression Inventory (BDI-II)

We used the French translation [22] of the original BDI-II questionnaire [23] for measuring the severity of depression. The questionnaire is composed of 21 items relating to depression symptoms such as hopelessness and irritability, cognitions such as guilt or feelings of being punished as well as physical symptoms such as fatigue, weight loss, and lack of interest in sex. The cut-offs used are: <10: normal score, 10-18: mild depression, 19-29: moderate depression, and >30: severe depression [24].

Hospital Anxiety and Depression Scale (HAD)

This self-assessment scale has been developed and found to be a reliable instrument for detecting states of depression and anxiety in the setting of a hospital medical outpatient clinic [25]. It is composed of 14 items, with 7 items evaluating the anxiety and the 7 other items evaluating the depression. The cut-offs used are: $\leq 7$ : no anxiety or depression, 8-10: some elements for, or $\geq 11$ : many elements for anxiety or depression.

\section{Eating Disorders Evaluation}

To examine pathological eating habits and the psychopathology around them, we used the French version of the Eating Disorder Examination Questionnaire (EDE-Q) [26]. The EDE-Q encompasses four subscales (Restraint, Eating Concern, Shape Concern, and Weight Concern) and a global score for symptoms and behaviors within the past 28 days. The possible values between 0 and 6 indicated no ED symptoms in the lower end of the range and distinct ED pathology in the higher end.

The Three-Factor Eating Questionnaire (TFEQ) [27] was used to complete eating behavior evaluation. The TFEQ is based on 51 items measuring the following dimensions: cognitive restraint of eating (factor I, 21 items), disinhibition (factor II, 16 items), and hunger (factor III, 14 items). Each item scores either 0 or 1 point. The minimum score for factors I-II-III is therefore 0-0-0, the possible maximum score 21-16-14.

\section{QoL Assessment}

The QoL was evaluated by the Impact of Weight on QoL (IWQOL-Lite ${ }^{\odot}$ ) questionnaire [28], a 31-item questionnaire evaluating social, professional and sexual life, self-esteem, and mobility. Higher scores are sign of a better QoL in the domain evaluated. 
Pataky et al.: Effects of a Weight Loss Program on Metabolic Syndrome, Eating Disorders and Psychological Outcomes: Mediation by Endocannabinoids?

Statistical Analysis

At the end of the follow-up (12 months),patients were assigned to 1 of 3 following groups according to body weight evolution: weight loss group (patients who lost $>2.5 \%$ of initial body weight); weight-stable group (body weight variations $\pm 2.5 \%$ ); and weight gain group (patients who showed an increase of $>2.5 \%$ of initial body weight). Patient characteristics were compared using the ANOVA (parametric data) followed by Fischer post-hoc test analysis or the Kruskal-Wallis test by ranks (non-parametric data).

Relationships between different parameters were evaluated by simple and multiple regression analysis. ANOVA for repeated measurements was used to investigate the modifications occurring after the intervention. The differences in percent prevalence of metabolic normality were evaluated by chi-square test. Univariate and multivariate logistic regression analysis was used to establish predictive factors of weight loss evolution.

Results are expressed as mean \pm SD. All statistical analyses were performed with the STATA software (v. 10; Stata Corporation, College Station, TX, USA). The alpha was set at 0.05 (two-sided).

\section{Results}

\section{Program Attendance}

From the total cohort of 114 patients, 87 patients (76.3\%) have completed the follow-up at the end of the program. Among completers, 35 patients $(40 \%)$ lost weight $(-9.1 \pm 8.6 \mathrm{~kg}$; $-8.2 \%), 39$ patients ( $45 \%)$ presented stable weight $(-0.2 \pm 1.4 \mathrm{~kg} ;-0.2 \%)$, and 13 patients $(15 \%)$ increased their body weight $(+5.8 \pm 3.4 \mathrm{~kg} ;+5.8 \%)$. The anthropometric and cardiometabolic characteristics of the subjects according to body weight evolution at 12 months are presented in table 1 . No statistically significant differences between the 3 groups in terms of baseline characteristics were observed.

The drop-out rate was $23.7 \%$, with 27 subjects who have decided to interrupt the followup before the end of the program. 24 of them were successfully contacted after the end of the program. Among the contacted subjects, 16 had lost weight (mean weight loss $13.9 \pm 11.9 \mathrm{~kg}$; 7 of them had undergone Roux-en-Y gastric bypass) and 1 patient had stable weight. Five patients gained weight (mean weight gain $6.0 \pm 2.9 \mathrm{~kg}$ ). Two patients did not want to share their last value of body weight with the HCP since they had stopped the program.

\section{Weight Loss Group}

Among subjects with weight loss $(n=35)$, patients lost mainly fat mass $(-7.9 \pm 8.0 \mathrm{~kg}$; $\mathrm{p}<0.001)$ and reduced waist circumference $(-7.8 \pm 7.5 \mathrm{~cm} ; \mathrm{p}<0.001)$. The decrease in lean body mass was low $(-1.22 \pm 2.96 \mathrm{~kg} ; \mathrm{p}=0.02)$. The systolic blood pressure significantly decreased $(-5.1 \pm 14.5 \mathrm{~mm} \mathrm{Hg}$; $=0.04)$.

Among laboratory parameters, we observed a significant decrease in fasting plasma glucose (baseline: $5.8 \pm 1.0 \mathrm{mmol} / \mathrm{l}$, after 12 months: $5.3 \pm 0.7 \mathrm{mmol} / \mathrm{l} ; \mathrm{p}=0.002$ ) and ALAT (baseline: $30.3 \pm 21.1 \mathrm{U} / \mathrm{l}$, after 12 months: $22.3 \pm 9.7 \mathrm{U} / \mathrm{l} ; \mathrm{p}=0.04$ ). No significant differences with regard to ASAT, GGT, plasma lipids, or hs-CRP have been observed between baseline and 12-month follow-up.

With respect to endocannabinoids, we observed a statistically significant decrease of 2-AG (baseline: $13.7 \pm 11.4 \mathrm{ng} / \mathrm{ml}$, after 12 months: $6.9 \pm 4.5 \mathrm{ng} / \mathrm{ml} ;, \mathrm{p}=0.02$ ). There was a tendency to reduction of OEA and PEA levels without reaching statistically significant differences ( $p=0.08$ for both). No changes of AEA have been observed.

The weight loss group became physically more active during the weight loss program (baseline: $244 \pm 124$ counts/day, after 12 months: $279 \pm 102$ counts/day; $p=0.01$ ) and slightly, but statistically significantly increased the percent protein intake (baseline: $17.4 \pm$ $4.0 \%$, after 12 months: $18.9 \pm 4.9 \%$; $=0.03$ ) (table 2 ). 


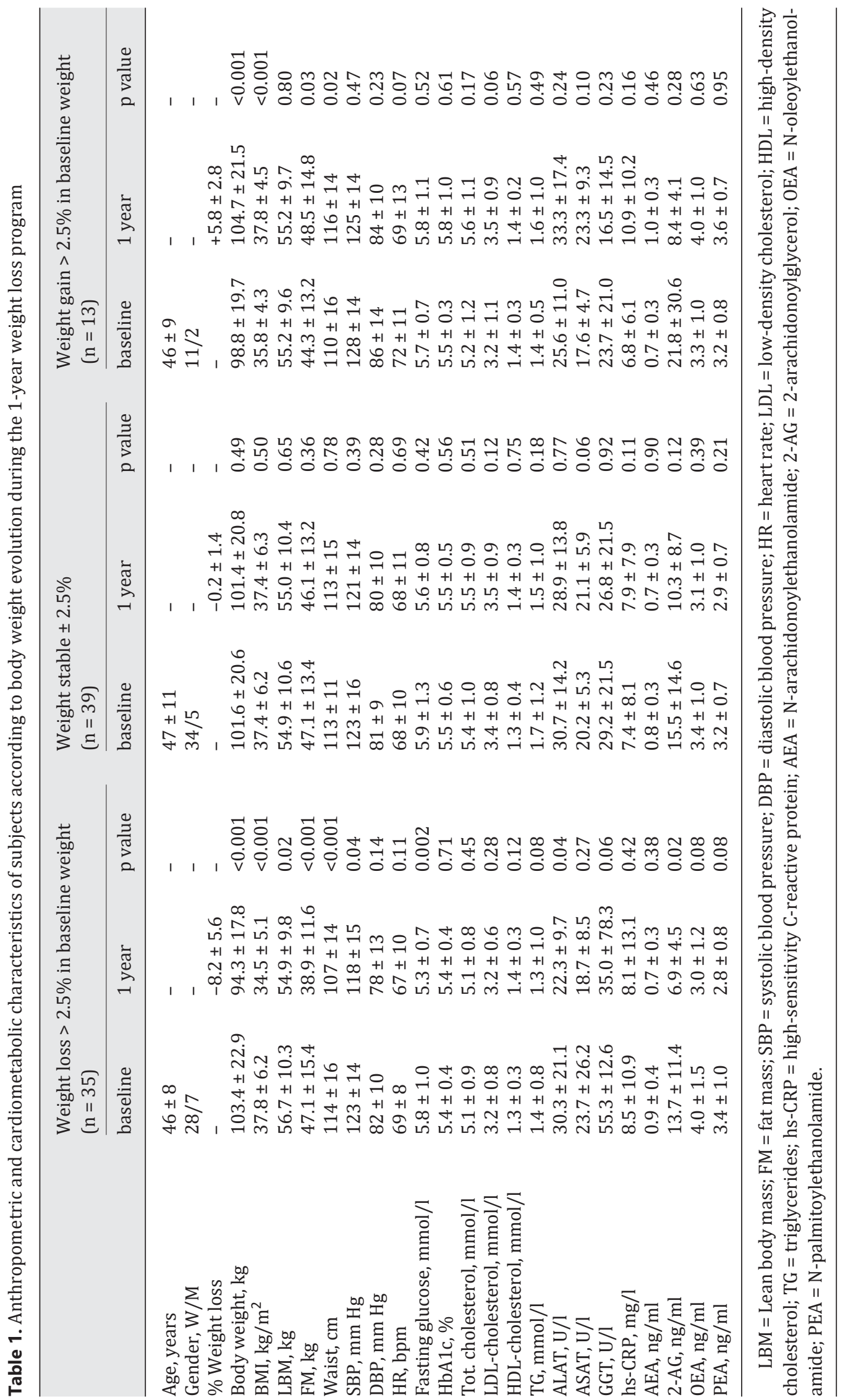



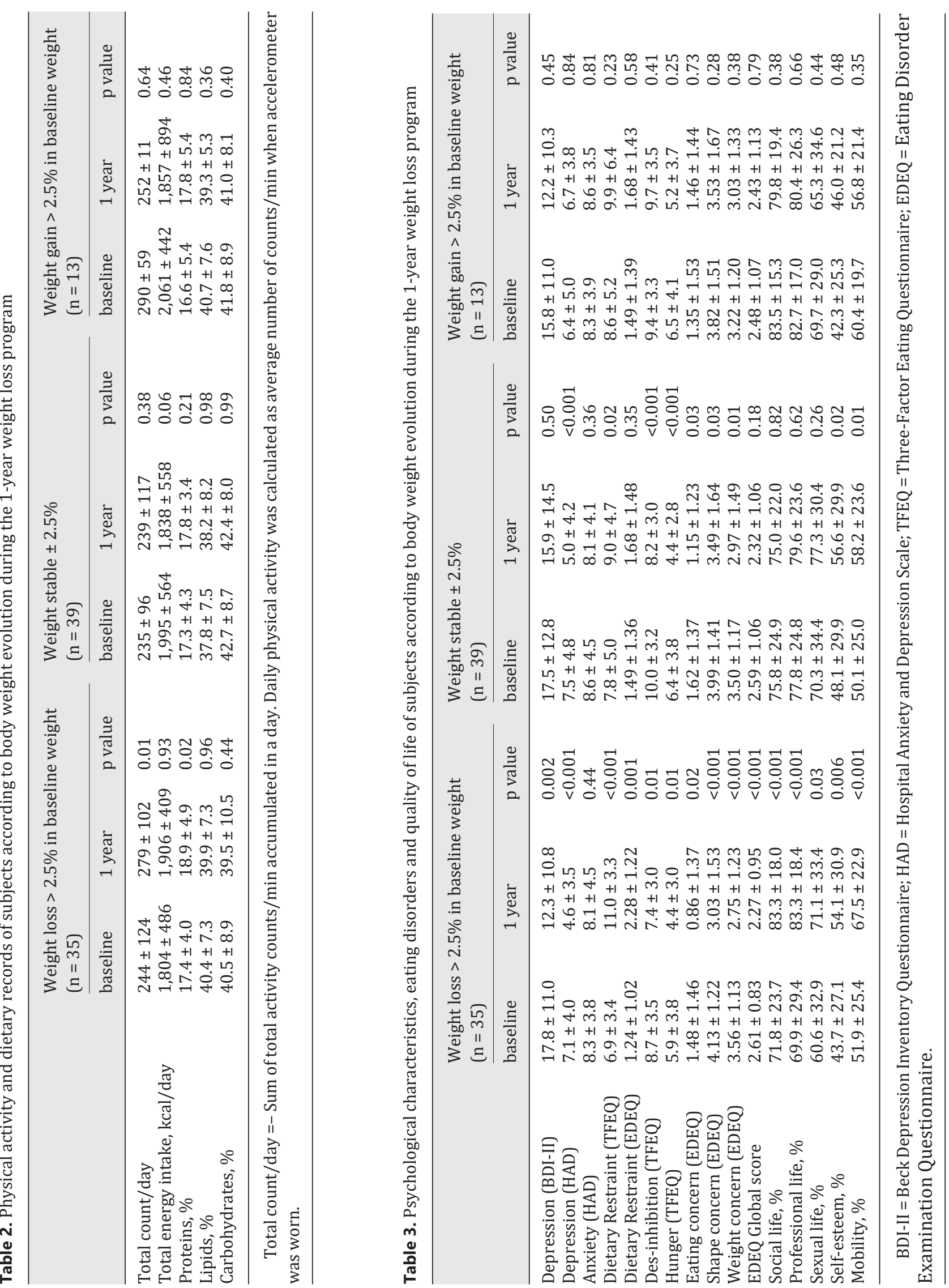
All psychological parameters, ED as well as QoL (table 3) statistically significantly improved during the 12-month weight loss program, with the exception of anxiety score which did not change. The dietary restraint increased, as evaluated by both TFEQ and EDEQ questionnaires $(\mathrm{p}<0.001$ and $\mathrm{p}=0.001$, respectively).

\section{Weight-Stable and Weight Gain Groups}

No changes in terms of body composition and laboratory parameters were observed in both weight-stable $(n=39)$ and weight gain $(n=13)$ groups, except for the increase in fat mass and waist circumference for the weight gain group (table 1).

From the psychological point of view, we noticed statistically significant improvements among the weight-stable group (table 3). Namely, the depression score (HAD) was lower $(p<0.001)$, ED improved (increase of dietary restraint $(p=0.02)$ as well as decrease of disinhibition $(\mathrm{p}<0.001)$, hunger $(\mathrm{p}<0.001)$, eating $(\mathrm{p}=0.03)$, shape $(\mathrm{p}=0.03)$ and weight concern $(p=0.01)$ ). Different aspects of QoL such as self-esteem $(p=0.02)$ and mobility $(p=0.01)$ improved (table 3 ) in the weight-stable group.

No changes in terms of psychological parameters, ED, or QoL were noticed among the weight gain group.

\section{Factors Related to Body Weight Evolution}

When analyzing in a univariate logistic regression model the following differences between baseline and 12-month follow-up (as expressed as delta values) were significantly associated with the weight loss at 12 -month follow-up: increase of dietary restraint (OR 0.82 (0.71-0.95); $\mathrm{p}=0.009$ ), mobility (OR 0.96 (0.93-0.99); $\mathrm{p}=0.01$ ), social life (OR 0.96 (0.93$0.9) ; p=0.004$ ) and decrease of shape concern (OR $1.66(1.09-2.52) ; p=0.02$ ).

In a multivariate logistic regression model, the increase of dietary restraint (OR 0.81 $(0.69-0.96) ;, p=0.02)$ and decrease of shape concern (OR $1.68(1.01-2.79) ; p=0.04)$ remained statistically significant.

\section{MS Evolution}

At baseline, 100 patients (87.7\%) of the 114 patients presented with MS and 14 (12.3\%) were MS-free according to IDF definition [15].

At 12-month follow-up, we missed some data for 6 subjects among the completers $(\mathrm{n}=$ 87). Thus, the proportion of patients with or without MS was calculated in 81 patients. Among these completers, 61 patients $(75.3 \%)$ became free of MS and 20 patients $(24.7 \%)$ still presented with MS at 12 months. No patient has developed MS during the follow-up ( $\mathrm{p}=$ 0.032). The remission of MS was independent of body weight ( $\mathrm{p}=0.35)$.

In subjects who became free of MS, we noticed significantly lower baseline PEA $(3.3 \pm 0.8$ $\mathrm{ng} / \mathrm{ml}$ vs. $4.4 \pm 1.3 \mathrm{ng} / \mathrm{ml} ; \mathrm{p}=0.01)$, total daily energy intake $(1,678 \pm 475$ vs. $2,213 \pm 520$ $\mathrm{kcal} /$ day; $\mathrm{p}=0.02$ ), and amount of consumed saturated fatty acids (SFA) (26.3 \pm 8.2 vs. 36.8 $\pm 16.5 \mathrm{~g} /$ day; $\mathrm{p}=0.04$ ), when compared with subjects who still showed MS at follow-up in the weight loss subgroup.

Using a univariate logistic regression model, we identified baseline PEA to be related to MS remission (OR 2.20 (1.08-4.50); $\mathrm{p}=0.03$ ).

The changes of depression score (as expressed as delta values according to BDI-II) were significantly associated with the MS remission at 12 months (OR $1.10(1.02-1.19) ; p=0.01)$.

\section{Plasma Endocannabinoids}

When analyzing by simple regression analysis, we observed a positive relationship between baseline PEA and baseline waist circumference $\left(p=0.005, R^{2}=0.08\right)$, fasting glucose $\left(p<0.0001, R^{2}=0.12\right)$, total cholesterol $\left(p=0.001, R^{2}=0.11\right)$, triglycerides $\left(p=0.001, R^{2}=\right.$ 
$0.11)$ as well as LDL-cholesterol $\left(p=0.03, R^{2}=0.05\right)$. There was a positive relationship between baseline PEA and baseline depression score assessed by HAD questionnaire ( $\mathrm{p}=$ $0.002, \mathrm{R}^{2}=0.29$ ). There was no relationship between PEA and body weight or BMI.

\section{Discussion}

We have seen that the structured, multidisciplinary and patient-educational lifestyle weight loss program induced a weight reduction in $40 \%$ of participants at 12 -month followup. This weight loss, corresponding to $8.2 \%$ of baseline weight, resulted in significant improvement of cardiometabolic and psychological parameters, ED, and QoL (tables 1-3). These results confirm previous observations reporting clinically meaningful health improvements after a moderate weight loss [29-31].

In addition, our study clearly indicates that, even in the groups with absence of weight loss, an educational program exerts beneficial effects on patient's QoL and also contributes to the improvement of several psychological parameters, namely those related to weight, body shape and eating concerns, reduction of both disinhibition and hunger feelings, and improvement of depression score (table 3). Some aspects of QoL are also improved in the absence of weight loss. It is well known that all these psychological traits largely contribute to the development of pathological eating habits.

Recently, a meta-analysis of 44 studies implementing DPP lifestyle interventions in US clinical settings published between 2005 and 2015 showed that, after a mean follow-up of 9.3 months, the mean weight loss was $3.8 \mathrm{~kg}$ in intervention arms. This relatively modest weight reduction was associated with favorable changes in blood pressure, plasma cholesterol, and glucose [29]. The analyzed studies retained the DPP's core principles of calorie-restricted diets and 150 min of moderate-intensity exercise per week, and mainly group sessions were administrated. However, psychological or QoL-related characteristics were not assessed or reported.

Similarly, another meta-analysis assessing the effectiveness of lifestyle interventions (79 studies, follow-up varying from 12 to 54 months) on glycemic indicators among adults without impaired glucose tolerance or diabetes showed a weight loss of $4.0 \mathrm{~kg}$ to be accompanied by improvement of both plasma glucose and insulin sensitivity [30].

The MOVE! lifestyle change program showed a mean weight change of $-2.8 \%$ and a $33 \%$ reduction of diabetes incidence among 238,000 veterans with 12-month data [31].

In our study, the mean weight loss was $9.1 \mathrm{~kg}(8.2 \%)$ in the weight loss group with significant improvements of blood pressure and fasting glucose after 12 months. Interestingly, but not surprisingly, patients who lost weight presented increase in dietary restriction and protein consumption during the program, became physically more active (table 2), and improved their mood and eating disorders as well as QoL (table 3). However, increase in dietary restraint score (evaluated by both TFEQ and EDEQ questionnaires) was not reflected by decrease of total daily caloric consumption, as assessed by food diary. Dietary record as used in the present study is based on self-reported dietary intake, which is liable to potential biases and often underestimates the energy intake [32], particularly at the beginning of a weight loss program. The underreporting of energy intake (related to measured total energy expenditure) in obese subjects could be as high as $25-50 \%$ of total calories [18]. In our weight loss group, $77 \%$ of patients underreported their caloric consumption, with a mean difference between reported energy intake and measured basal metabolic rate of $125 \mathrm{kcal} /$ day (data not shown). Roughly, the total body weight loss of $9.1 \mathrm{~kg}$ during 12 months represents a daily caloric deficit of $190 \mathrm{kcal}$. The absence of this caloric deficit (as documented by self-reported food diary) necessary to lose weight could be explained by the mentioned underreporting at 
Pataky et al.: Effects of a Weight Loss Program on Metabolic Syndrome, Eating Disorders and Psychological Outcomes: Mediation by Endocannabinoids?

baseline on one side and the modest increase in physical activity at follow-up on the other side.

It has been shown that cognitive behavioral treatment including motivational interviewing can help patients to support commitment to change and to address maladaptive thinking $[33,34]$. The weight loss program of our study offers both group sessions and individual face-to-face appointments to patients during 1 year. The patient educational approach and behavioral therapy have been designed to provide obese patients with techniques for adopting dietary and physical activity recommendations on regular basis and without prescribing any kind of restrictive diet or intensive physical activity. Face-to-face appointments between the patient and his/her coach are encompassing also difficulties related to psychological and environmental issues (family, work and social life) in order to help patients with stress management and to avoid stress and/or personal problems' compensations by food.

Traditional lifestyle interventions focusing on weight loss as primary outcome ignore evidence that dieting may have important impact on eating behavior and unhealthy attitudes $[35,36]$, thus contributing to cyclic weight regain in a large proportion of obese people with more pronounced psychological suffering as a consequence. The absence of psychological and QoL evaluation in lifestyle studies could lead to underestimation of the psychological suffering due to obesity itself and after different weight loss programs.

In our study we also assessed psychological well-being which was significantly improved in both the weight loss and the weight-stable group. Even in absence of weight loss, patients with stable weight have significantly improved depression score (HAD), eating disorders and QoL (table 3). One could speculate that the patients who stabilized their weight may have prevented further weight gain during the 12 months.

In the whole population, $75 \%$ of subjects with MS at baseline improved their metabolic status and became free of MS at follow-up. When assessing the evolution of MS, we have seen that patients, who became free of MS at follow-up, had lower baseline caloric intake with particularly lower consumption of SFA than subjects without MS resolution. This is in line with studies showing the involvement of dietary SFA in the development of cardiovascular diseases and supporting the current dietary recommendations to reduce the intake of SFA [8, 37]. However, data showing relation between SFA intake and MS are scarce and surprisingly controversial, with some reports showing no effect of dietary SFA on chronic diseases [39]. On the other hand, higher dietary SFA were associated with MS development independently of BMI, physical activity, and smoking status [40]. In a cross-sectional study of 4,677 adults, Hosseinpour-Niazi et al. [41] showed that increased SFA intakes were positively associated with the prevalence of MS, independently of total dietary fat. It has been suggested that augmented alimentary short-chain fatty acids in an animal model could promote conversion of SFA to oleate and thus to be a player in MS development [42].

Another original observation from our study is that plasma levels of PEA were significantly related to the MS evolution. Patients who became free of MS at 12 months presented lower baseline PEA than patients who still fulfilled the criteria for MS. Lower baseline PEA contributed to MS resolution (OR 2.20 (1.08-4.50)) independently of BMI. Among psychological parameters, there was a relationship between baseline plasma PEA and HAD depression score $\left(p=0.002, R^{2}=0.29\right)$. To our best knowledge, these observations have never been reported in the literature. On the other hand, the known central nervous system effects of cannabinoid type 1 receptor (CB1) blockers (e.g., rimonabant) on mood and depression could be mediated by this endocannabinoid congener [10].

We have previously suggested some potential pathophysiological pathways mediated by PEA and OEA, reducing adipose tissue inflammation [43]. In a prospective cohort of morbidly obese patients, massive weight loss induced by gastric bypass was related to a significant 
increase in all measured endocannabinoids (PEA, OEA, 2-AG, AEA) in subcutaneous adipose tissue (SAT). This was accompanied by down-regulation of CB1 receptors and PPAR-alpha mRNA expression as well as improvement of inflammatory profile in SAT [43]. Our group also showed recently that the circulating levels of PEA were correlated with coronary function parameters [11]. Thus, plasma PEA levels might represent a potential biomarker of coronary dysfunction [11] and, in the same manner, might be predictive of metabolic evolution associated with weight loss. However, data in the literature on PEA or other endocannabinoids in relation to MS are scarce.

The 12-month follow-up could be considered as a study limitation. A longer follow-up would be clinically more meaningful. Long-term follow-up studies on lifestyle interventions in obesity are rare. As mentioned in a recent meta-analysis, the mean duration of follow-up among 44 studies was 9.3 months [29].

The strengths of our study are the prospective design and the evaluation of multiple biological parameters, including plasma endocannabinoid measurement and determination of psychological outcomes, eating disorders and QoL in obese patients during a non-dieting weight loss program. The majority of studies evaluating weight loss are lifestyle interventionbased, often with caloric restriction or diet and/or physical activity prescription. In our study, we used patient education tailored to patient's individual needs, motivational interviewing as well as combined group sessions and face-to-face appointments with no dietary or physical activity prescription at any time during the program.

We report for the first time a relationship between plasma PEA and metabolic risk factors as well as depression scores, with metabolic evolution being possibly mediated by PEA.

In conclusion, we could show that a multidisciplinary and patient-educational weight loss non-dieting program induces health benefits in the majority of patients. Among patients with MS at baseline, 75\% have resolved this constellation of cardiometabolic risk factors at 12 months. In addition to weight loss and improvement of cardiometabolic profile, the weight loss program could be beneficial in terms of psychological outcomes, eating disorders, and QoL improvement, even in subjects with no weight loss during the program.

We report an interesting observation on plasma PEA who might be a potential biomarker of metabolic improvements and also severity of depression in obese patients. This should be confirmed by larger clinical studies.

\section{Acknowledgments}

All co-authors had full access to all of the data in the study and take responsibility for the integrity of the data and the accuracy of the data analysis.

\section{Disclosure Statement}

The authors declare no conflict of interest. 
Pataky et al.: Effects of a Weight Loss Program on Metabolic Syndrome, Eating Disorders and Psychological Outcomes: Mediation by Endocannabinoids?

\section{References}

-1 Jensen MD, Ryan DH, Apovian CM, Ard JD, Comuzzie AG, Donato KA, Hu FB, Hubbard VS, Jakicic JM, Kushner RF, Loria CM, Millen BE, Nonas CA, Pi-Sunyer FX, Stevens J, Stevens VJ, Wadden TA, Wolfe BM, Yanovski SZ: 2013 AHA/ACC/TOS guideline for the management of overweight and obesity in adults: a report of the American College of Cardiology/American heart Association Task Force on Practice Guidelines and The Obesity Society. J Am Coll Cardiol 2014;63:2985-3023.

-2 Knowler WC, Barrett-Connor E, Fowler SE, Hamman RF, Lachin JM, Walker EA, Nathan DM: Reduction in the incidence of type 2 diabetes with lifestyle intervention or metformin. N Engl J Med 2002;346:393-403.

-3 Knowler WC, Fowler SE, Hamman RF, Christophi CA, Hoffman HJ, Brenneman AT, Brown-Friday JO, Goldberg R, Venditti E, Nathan DM: 10-year follow-up of diabetes incidence and weight loss in the diabetes prevention program outcomes study. Lancet 2009;374:1677-1686.

4 Dall TM, Storm MV, Semilla AP, Wintfeld N, O'Grady M, Narayan KM: Value of lifestyle intervention to prevent diabetes and sequelae. Am J Prev Med 2015;48:271-280.

-5 Magkos F, Fraterrigo G, Yoshino J, Luecking C, Kirbach K, Kelly SC, de Las Fuentes L, He S, Okunade AL, Patterson BW, Klein S: Effects of moderate and subsequent progressive weight loss on metabolic function and adipose tissue biology in humans with obesity. Cell Metab 2016;23:591-601.

-6 Miller WC: How effective are traditional dietary and exercise interventions for weight loss? Med Sci Sports Exerc 1999;31:1129-1134.

7 Gaesser GA: Thinness and weight loss: beneficial or detrimental to longevity? Med Sci Sports Exerc 1999;31: 1118-1128.

-8 Cota D, Marsicano G, Tschop M, Grubler Y, Flachskamm C, Schubert M, Auer D, Yassouridis A, Thone-Reineke C, Ortmann S, Tomassoni F, Cervino C, Nisoli E, Linthorst AC, Pasquali R, Lutz B, Stalla GK, Pagotto U: The endogenous cannabinoid system affects energy balance via central orexigenic drive and peripheral lipogenesis. J Clin Invest 2003;112:423-431.

-9 Gatta-Cherifi B, Cota D: New insights on the role of the endocannabinoid system in the regulation of energy balance. Int J Obes (Lond) 2016;40:210-219.

10 Pataky Z, Gasteyger C, Ziegler O, Rissanen A, Hanotin C, Golay A: Efficacy of rimonabant in obese patients with binge eating disorder. Exp Clin Endocrinol Diabetes 2013;121:20-26.

11 Quercioli A, Carbone F, Bonaventura A, Liberale L, Pataky Z, Thomas A, Lenglet S, Lauer E, Golay A, Dallegri F, Di Marzo V, Schindler TH, Montecucco F: Plasma palmitoylethanolamide (PEA) as a potential biomarker for impaired coronary function. Int J Cardiol 2017;231:1-5.

12 Miller WR, Rollnick S: Motivational Interviewing, 3rd ed. New York, The Guilford Press, 2013.

13 Scherrer-Burri F, Golay A: Developing nurses' motivational interviewing skills through coaching (in French). Soins 2013:23-26.

14 Friedewald WT, Levy RI, Fredrickson DS: Estimation of the concentration of low-density lipoprotein cholesterol in plasma, without use of the preparative ultracentrifuge. Clin Chem 1972;18:499-502.

15 Alberti KG, Zimmet P, Shaw J: The metabolic syndrome - a new worldwide definition. Lancet 2005;366:10591062.

16 Quercioli A, Montecucco F, Pataky Z, Thomas A, Ambrosio G, Staub C, Di Marzo V, Ratib O, Mach F, Golay A, Schindler TH: Improvement in coronary circulatory function in morbidly obese individuals after gastric bypass-induced weight loss: relation to alterations in endocannabinoids and adipocytokines. Eur Heart J 2013;34:2063-2073.

17 Weir JB: New methods for calculating metabolic rate with special reference to protein metabolism. J Physiol 1949;109:1-9.

18 Westerterp KR, Goris AH: Validity of the assessment of dietary intake: problems of misreporting. Curr Opin Clin Nutr Metab Care 2002;5:489-493.

19 Ekelund U, Griffin SJ, Wareham NJ: Physical activity and metabolic risk in individuals with a family history of type 2 diabetes. Diabetes Care 2007;30:337-342.

20 Freedson PS, Melanson E, Sirard J: Calibration of the Computer Science and Applications, Inc. accelerometer. Med Sci Sports Exerc 1998;30:777-781.

21 Masse LC, Fuemmeler BF, Anderson CB, Matthews CE, Trost SG, Catellier DJ, Treuth M: Accelerometer data reduction: a comparison of four reduction algorithms on select outcome variables. Med Sci Sports Exerc 2005; 37:S544-554.

22 Beck AT, Steer RA, Brown GK: BDI-II, inventaire de dépresion de beck, manuel. Paris, éditions du centre de psychologie appliquée, 1996.

23 Beck AT, Steer RA, Ball R, Ranieri W: Comparison of Beck Depression Inventories -Ia and -II in psychiatric outpatients. J Pers Assess 1996;67:588-597.

24 Bouvard M, Cottraux J: Protocoles et échelles d'évaluation en psychiatrie et en psychologie. Paris, Masson, 2000.

25 Zigmond AS, Snaith RP: The hospital anxiety and depression scale. Acta Psychiatr Scand 1983;67:361-370.

-26 Carrard I, Rebetez MM, Mobbs 0, Van der Linden M: Factor structure of a French version of the eating disorder examination-questionnaire among women with and without binge eating disorder symptoms. Eat Weight Disord 2015;20:137-144. 
Pataky et al.: Effects of a Weight Loss Program on Metabolic Syndrome, Eating

Disorders and Psychological Outcomes: Mediation by Endocannabinoids?

-27 Stunkard AJ, Messick S: The three-factor eating questionnaire to measure dietary restraint, disinhibition and hunger. J Psychosom Res 1985;29:71-83.

28 Kolotkin RL, Crosby RD, Williams GR: Health-related quality of life varies among obese subgroups. Obes Res 2002;10:748-756.

29 Mudaliar U, Zabetian A, Goodman M, Echouffo-Tcheugui JB, Albright AL, Gregg EW, Ali MK: Cardiometabolic risk factor changes observed in diabetes prevention programs in us settings: A systematic review and metaanalysis. PLoS Med 2016;13:e1002095.

-30 Zhang X, Imperatore G, Thomas W, Cheng YJ, Lobelo F, Norris K, Devlin HM, Ali MK, Gruss S, Bardenheier B, Cho P, Garcia de Quevedo I, Mudaliar U, Saaddine J, Geiss LS, Gregg EW: Effect of lifestyle interventions on glucose regulation among adults without impaired glucose tolerance or diabetes: a systematic review and meta-analysis. Diabetes Res Clin Pract 2017;123:149-164.

-31 Jackson SL, Long Q, Rhee MK, Olson DE, Tomolo AM, Cunningham SA, Ramakrishnan U, Narayan KM, Phillips LS: Weight loss and incidence of diabetes with the Veterans Health Administration MOVE! lifestyle change programme: an observational study. Lancet Diabetes Endocrinol 2015;3:173-180.

-32 Schoeller DA: Limitations in the assessment of dietary energy intake by self-report. Metabolism 1995;44: 18-22.

33 DiLillo V, West DS: Motivational interviewing for weight loss. Psychiatr Clin North Am 2011;34:861-869.

-34 Wadden TA, West DS, Delahanty L, Jakicic J, Rejeski J, Williamson D, Berkowitz RI, Kelley DE, Tomchee C, Hill JO, Kumanyika S: The look ahead study: a description of the lifestyle intervention and the evidence supporting it. Obesity (Silver Spring) 2006;14:737-752.

-35 Borkoles E, Carroll S, Clough P, Polman RC: Effect of a non-dieting lifestyle randomised control trial on psychological well-being and weight management in morbidly obese pre-menopausal women. Maturitas 2016;83: 51-58.

-36 Sirohi S, Van Cleef A, Davis JF: Patterned feeding induces neuroendocrine, behavioral and genetic changes that promote palatable food intake. Int J Obes (Lond) 2017;41:412-419.

-37 Mayneris-Perxachs J, Guerendiain M, Castellote AI, Estruch R, Covas MI, Fito M, Salas-Salvado J, MartinezGonzalez MA, Aros F, Lamuela-Raventos RM, Lopez-Sabater MC: Plasma fatty acid composition, estimated desaturase activities, and their relation with the metabolic syndrome in a population at high risk of cardiovascular disease. Clin Nutr 2014;33:90-97.

-38 Howard BV, Van Horn L, Hsia J, Manson JE, Stefanick ML, Wassertheil-Smoller S, Kuller LH, LaCroix AZ, Langer RD, Lasser NL, Lewis CE, Limacher MC, Margolis KL, Mysiw WJ, Ockene JK, Parker LM, Perri MG, Phillips L, Prentice RL, Robbins J, Rossouw JE, Sarto GE, Schatz IJ, Snetselaar LG, Stevens VJ, Tinker LF, Trevisan M, Vitolins MZ, Anderson GL, Assaf AR, Bassford T, Beresford SA, Black HR, Brunner RL, Brzyski RG, Caan B, Chlebowski RT, Gass M, Granek I, Greenland P, Hays J, Heber D, Heiss G, Hendrix SL, Hubbell FA, Johnson KC, Kotchen JM: Low-fat dietary pattern and risk of cardiovascular disease: the Women's Health Initiative Randomized Controlled Dietary Modification Trial. JAMA 2006;295:655-666.

-39 Harding AH, Day NE, Khaw KT, Bingham S, Luben R, Welsh A, Wareham NJ: Dietary fat and the risk of clinical type 2 diabetes: the European prospective investigation of Cancer-Norfolk Study. Am J Epidemiol 2004;159: 73-82.

40 Warensjo E, Sundstrom J, Lind L, Vessby B: Factor analysis of fatty acids in serum lipids as a measure of dietary fat quality in relation to the metabolic syndrome in men. Am J Clin Nutr 2006;84:442-448.

-41 Hosseinpour-Niazi S, Mirmiran P, Fallah-Ghohroudi A, Azizi F: Combined effect of unsaturated fatty acids and saturated fatty acids on the metabolic syndrome: Tehran Lipid and Glucose Study. J Health Popul Nutr 2015; 33:5.

-42 Singh V, Chassaing B, Zhang L, San Yeoh B, Xiao X, Kumar M, Baker MT, Cai J, Walker R, Borkowski K, Harvatine KJ, Singh N, Shearer GC, Ntambi JM, Joe B, Patterson AD, Gewirtz AT, Vijay-Kumar M: Microbiota-dependent hepatic lipogenesis mediated by stearoyl coa desaturase 1 (SCD1) promotes metabolic syndrome in TLR5deficient mice. Cell Metab 2015;22:983-996.

43 Montecucco F, Lenglet S, Quercioli A, Burger F, Thomas A, Lauer E, da Silva AR, Mach F, Vuilleumier N, BobbioniHarsch E, Golay A, Schindler TH, Pataky Z: Gastric bypass in morbid obese patients is associated with reduction in adipose tissue inflammation via N-oleoylethanolamide (OEA)-mediated pathways. Thromb Haemost 2015; 113:838-850 